\title{
Contrarian Stocks: Are They Exist in Indonesian and Malaysian Capital Market?
}

\author{
Samuel Hasudungan ${ }^{1}$, Budi Purwanto ${ }^{2}$, Nunung Nuryartono ${ }^{3}$, Maswati Abd Talib ${ }^{4}$, \\ \{hasudungansamuel@apps.ipb.ac.id ${ }^{1}$, budipurwanto@apps.ipb.ac.id ${ }^{2}$, nuryartono@apps.ipb.ac.id ${ }^{3}$, \\ maswati@upm.edu.my ${ }^{4}$. \\ Master Programme in Management, Sekolah Pascasarjana, IPB University, Babakan, Dramaga, \\ Bogor, West Java, 16680, Indonesia ${ }^{1}$ \\ Faculty of Economics and Management, IPB University, Babakan, Dramaga, Bogor, West Java, \\ 16680, Indonesia ${ }^{2,3}$ \\ School of Business and Economics, UPM, UPM Serdang, Malaysia ${ }^{4}$
}

\begin{abstract}
The purpose of this study is to conduct an empirical test of the contrarian stock under bullish and bearish conditions in Indonesia and Malaysia stock market. The objectives of this study are: (1) to identify bullish and bearish periods in Indonesian and Malaysian Stock Exchange; (2) to identify contrarian stock during bullish and bearish period; and (3) to evaluate a portfolio performance with and without the contrarian stock. Samples for this study are weekly price and volume from Jakarta Composite Index, FTSE BM 100 Index, and 625 companies listed on both index. In 2014 - 2019, there are 5 bullish and 4 bearish period in Indonesian market, and 3 bullish and 3 bearish period in Malaysian market. Contrarian stocks are found both in bullish and bearish in Indonesia, but only in bullsih in Malaysia. Portfolio with contrarian stock significantly has a lower risk than a portfolio without contrarian stock.
\end{abstract}

Keywords: Bearish, Bullish; Bursa Malaysia; Contrarian Stock; Indonesian Capital Market; Markov-switching Autoreggresive

\section{Introduction}

In the stock market, there is a term called contrarian strategy. Contrarian strategy was first formulated by De Bondt and Thaler [1,2], where they argued that prior "losers" stocks generally out-performed the market and the "winner" stocks were under-performed. Contrarian strategy is defined as a strategy that is against the market in transaction activities [3]. Beta is a notation that measures the systematic risk in a stock and the volatility of that stock to its market. A negative beta value means that the volatility of that stock's return is opposite to the volatility of the market's return. This is what is meant by contrarian stock's term, a stock which its volatility against the market, but still has a positive return. 
Respati, Purwanto, and Irwanto [4] in their research found that stocks with a negative beta value really exist in the Indonesian capital market. Interestingly, with those special characteristics of contrarian stocks, these stocks have a significant impact when included in the portfolio preparation. A portfolio that includes contrarian stocks in the portfolio significantly has a lower level of risk compared to portfolio without contrarian stocks [5]. On average, the addition of contrarian stocks in the portfolio is also able to increase the return and the value of the Sharpe ratio [5].

However, in practice, these contrarian stocks are often leave unnoticed in the portfolio selection. Optimum portfolio selection using the Single Index Model method will exclude stocks with a negative beta value in the selection of the portfolio. This happen because those stocks will make the value of the Expected Return to Beta (ERB) to be negative. The deletion of stocks with a negative ERB value opens the assumption that the expected return reduced by risk-free assets will be negative. But what if the stock with a negative beta value has a positive expected return instead? The ERB will remain negative so it will still eliminate the beta-negative stocks. To include the contrarian stock in the portfolio, we should try another portfolio selection method. Markowitz's Meanvariance Model is the answer to the problem above, where the Mean-variance model does not consider the ERB calculation so it can accommodate stocks with negative beta values with positive returns into the portfolio selection.

Markowitz is considered as the pioneer of modern portfolio theory [6]. But the analytical expression of Markowitz's mean-variance efficient frontier was derived in his single-period portfolio model which can't capture the dynamic nature of optimal portfolio allocation in practice. Many researchers extend the Markowitz's static optimization model into a dynamic model. Among them are Samuelson [7] who extend the model into dynamic and considered a discrete-time consumption investment model and $[8,9]$ who used stochastic optimal control in a continuous time model.

In recent years, using regime switching models in portfolio optimization became more popular. Regime switching model is used due to the intention to reflect the state of the market. Separating state of the market is important due to the evidence that business cycles are asymmetric [10]. With time-varying parameter, regime-switching model are obviously more realistic than constant parameter models to reflect the random market environment [6]. With a regime switching model, the state of market can be roughly divided into two states, bullish and bearish. Bullish is a condition when market price is rising or its return are positive. In contrast, bearish is a condition when market price is decline or its return are negative. One of the most popular method to do regime switching analysis is Markov Switching Autoregressive. 
Zhou and Yin extended Markowitz's mean-variance model under Markovian regime switching models in continuous time setting and a discrete time setting respectively [11]. After that, Markov switching autoregressive have been applied to many optimum portfolio selection, such as in Guidolin and Timmermann, Elliott and Siu, P. Chen and Yang, and Respati [5,6,12,13].

As we have stated in the paragraph above, Respati showed that contrarian stocks are proven to be found on the Indonesian capital market [5]. Logically, it will be easy for investors to identify contrarian stocks when the market is declining or bearish, because contrarian stock will experience bullish and easy to get positive returns. However, can contrarian stocks be found when the market is bullish? Because if the market is bullish, then contrarian stocks will move down and naturally stocks that move down will have a negative return. So, will the contrarian stocks will be found in bullish and bearish periods?

Other question about the contrarian stocks are rising. Are contrarian stocks also found in other countries? To answer this question, this research will be conducted in Indonesia and Malaysia. We use Indonesian stock market as sample to test whether the contrarian stock is constantly can be found when we analyzed in different period. We also use Malaysian stock market to test whether contrarian stock can be found in other countries. Both Indonesia and Malaysia are influential countries in the ASEAN region. Figure 1 below shows the Jakarta Composite Index (JCI) as the stock market indicator in Indonesia and the FTSE Bursa Malaysia 100 index as the stock market indicator in Malaysia, in 2014 2019. It can be seen that JCI was dominated by bullish, while the FTSE BM 100 was dominated by sideways - bearish condition. With such differences in overall market conditions, a comparison and analysis of contrarian stocks in Indonesia and Malaysia will produce a comprehensive study.

The objectives of this study are: (1) to identify the period of bullish and bearish period in Indonesian and Malaysian Stock Exchange; (2) to identify the contrarian stock in Indonesian and Malaysian Stock Exchange in both bullish and bearish periods; and (3) to evaluate the performance of the portfolio between a portfolio with the contrarian stock and without the contrarian stock.

The rest of this paper is organized in the following manner: Section 2 reviews relevant literature. Section 3 describes research methodology such as types and sources of data, research steps, and data processing and analyzing methods. Section 4 presents statistical and the empirical results. Section 5 concludes the paper. 


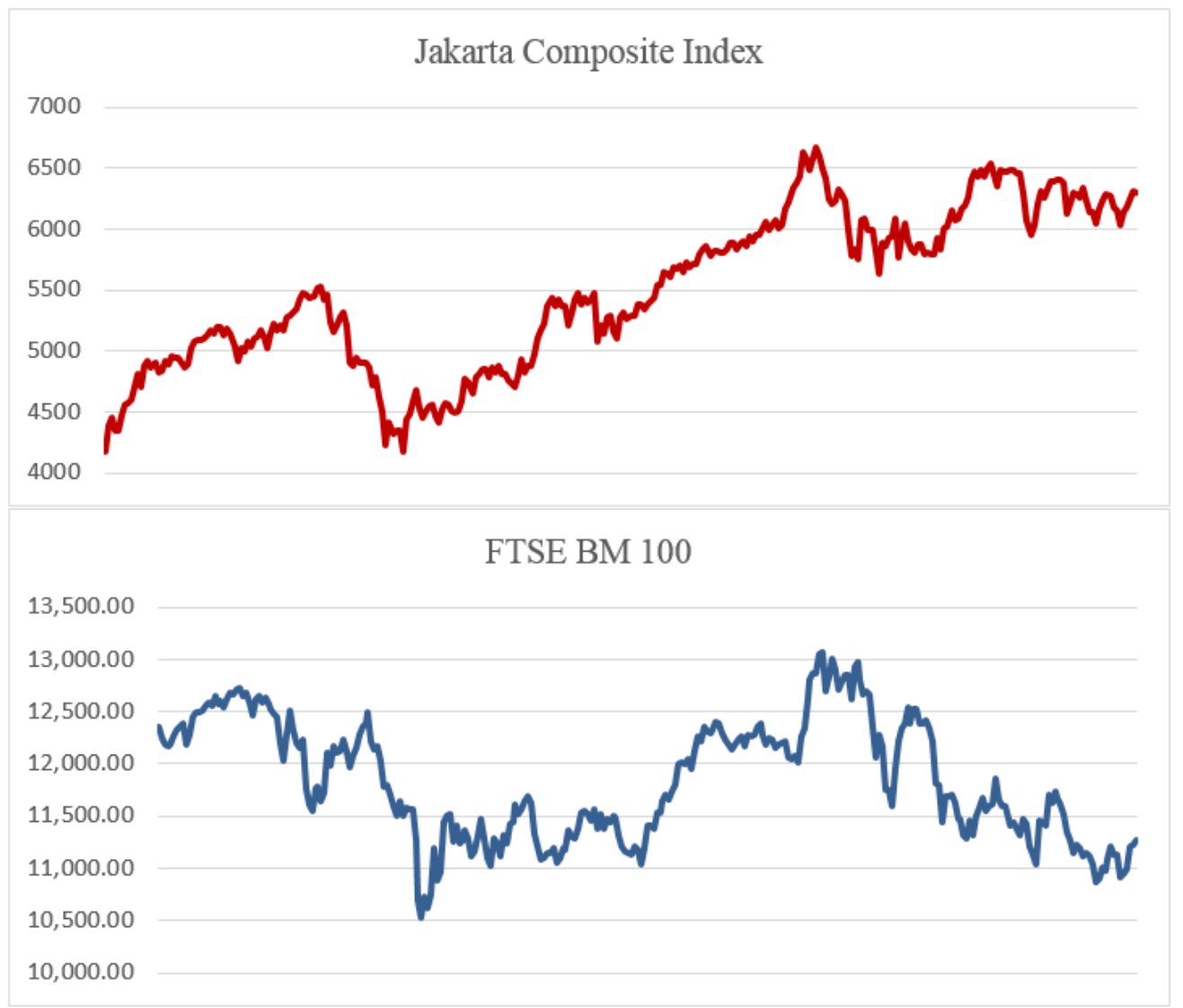

Fig. 1. Jakarta Composite Index (above) and FTSE Bursa Malaysia 100 (below) historical price from $2014-2019$.

\section{Literature Review}

\subsection{Bullish and Bearish}

Bullish is defined as a tendency that stock price is having an upward trend in the stock market, can be seen from the presence from increasing the stock price that penetrates the previous price's upper limit and if decreasing, the decreasing not penetrate the previous price's lower limit [14]. Otherwise, bearish is defined as a tendency that stock price is having a downward trend in the stock market, can be seen from the presence from decreasing stock price that penetrates the previous price's lower limit, and if increase, the increasing does not penetrate the previous price's upper limit. Fabozzi and Francis conduct research about alpha and beta in bullish and bearish conditions and showed that 
it needs to calculate beta separately from the bullish and bearish conditions [15]. Separating the calculation will give more accurate results and can accommodate changes in systematic beta risk due to changing market conditions.

\subsection{Markov Switching Model}

Generally, time series modeling is carried out using classic models such as Autoregressive Integrated Moving Average (ARIMA), Autoregressive Conditional Heteroscedastic (ARCH), and Generalized Autoregressive Conditional Heteroscedasticity (GARCH) [16]. However, the three models above are not considering changes in conditions, until Hamilton [17] introduced the Markov Switching Model, that also known as Regime Switching, where this model can be used as an alternative model in which there were changes in conditions or regimes. By capturing changing conditions, this model can capture more complex dynamics data from data movement.

The application of Markov Switching Model in the capital market has been widely used, for example in New York Stock Exchange [18], business cycle in United States of America [19], Indian Stock Market [20], and Indonesia [4].

\subsection{Optimum Portfolio Theory}

Diversifying in the portfolio is such topic that arose from in the middle of the $20^{\text {th }}$ century, but Modern Portfolio Theory first discovered by Harry M. Markowitz in 1952. Markowitz succeeded in distinguishing efficient portfolios from inefficient portfolios with a "set of efficient mean-variance combinations", or later known as "efficient frontier" [21]. The process of selecting a portfolio is divided into two stages [22]. The first stage begins with observing the securities, seeing their past performance, and ends with the emergence of confidence in the performance of these securities in the future. The second stage begins with the emergence of the beliefs that are relevant to their future performance and ends with portfolio selection. A portfolio is efficient if there are no other options that provide a higher return with the same level of risk, or lower risk with the same level of return [23]. The optimal number of shares to form an optimal portfolio is in the range of 12 to 20 joint shares [24].

\section{Research Methodology}

\subsection{Types and Sources of Data}


In this study, firstly we purposed to divide the market state into bullish and bearish. For this purpose, we use Jakarta Composite Index (JCI) and FTSE Bursa Malaysia (BM) 100 weekly closing price. After that, we identify the existence of contrarian stock from every stock listed in JCI or FTSE BM 100 index. There are 674 companies listed in JCI and 100 companies listed in FTSE BM 100. For that purpose, we use weekly closing price from all 774 companies listed in both indexes. All weekly closing price data is collected from January 2014 until December 2019.

A series of data sampling processes is conducted for those 774 companies. The sampling methodology uses purposive sampling method with some criteria as follows:

a. Listed on the JCI or FTSE BM 100 index during the observation period.

b. The company has complete weekly stock price data during the observation period.

c. The company did not conduct an IPO, not suspended by the regulators, or not removed from the stock exchange (delisting) during the observation period.

\subsection{Data Processing and Analyzing Methods}

\subsubsection{Measurement of return and risk free rate}

This study employs the measurement of returns from the index and individual shares price. The return is calculated using the formula:

$$
r_{i t}=\ln \left(\frac{P_{i t}}{P_{i(t-1)}}\right)
$$

Where $r_{i t}$ is return of security i in time t, $P_{i t}$ is price of security i in time t, and $P_{i(t-1)}$ is price of security i in 1 period before $\mathrm{t}$.

Risk-free rates, notated as $R_{f}$, use the 10-year government bond rate and inflation in both Indonesia and Malaysia. The formula is as follows:

$$
R_{f}=\frac{1+\text { Government Bond Rate }}{1+\text { Inflation rate }}
$$

\subsubsection{Markov Switching Autoregressive Model}

Markov Switching Autoregressive model is used as an alternative to model a time series data in which there are changes in conditions or regimes [16]. But before that, there are some prerequisites that must be met before carrying out a Markov analysis. The time series data used must be stationary. A time series data is said to be stationary if $\mathrm{E}\left(\mathrm{y}_{\mathrm{t}}\right)=\mu$ and $\operatorname{Var}\left(\mathrm{y}_{\mathrm{t}}\right)=\sigma^{2}$, constant for all $t$. Stationarity is divided into two, namely mean stationarity and variance stationarity. Visual stationarity testing can be done by making a plot and 
statistically it can be done with the Augmented Dickey Fuller (ADF) unit root test.

In the Augmented Dickey Fuller test, stationarity was examined by determining whether the autoregressive polynomial had a root right in the unit circle or near the unit circle [16]. $\mathrm{H}_{0}: \Phi=1$ (non-stationary data) and $\mathrm{H}_{1}: \Phi<$ 1 (stationary data) [25]. $\mathrm{H}_{0}$ is rejected (stationary data) if $\hat{\tau}_{\mu}<\mathrm{t}^{*}$ or if the probability value $<\alpha . t^{*}$ is a critical value of Dickey Fuller.

With:

$$
\hat{\tau}_{\mu}=\frac{\widehat{\Phi}_{1}^{*}}{\widehat{\mathrm{SE}}\left(\widehat{\Phi}_{1}^{*}\right)}
$$

$$
\begin{aligned}
& \widehat{\mathrm{SE}}\left(\widehat{\Phi}_{1}^{*}\right)=\mathrm{s}\left(\sum_{\mathrm{t}=2}^{n}\left(y_{t-1}-\bar{y}\right)^{2}\right)^{-\frac{1}{2}} \\
& \mathrm{~s}=\sum_{\mathrm{t}=2}^{n} \frac{\left(\nabla y_{t}-\widehat{\Phi}_{0}^{*}-\widehat{\Phi}_{0}^{*} y_{t-1}\right)^{2}}{(\mathrm{n}-3)}
\end{aligned}
$$

Hamilton formulates the modelling by switching on the value of mean and variance, as follows [26]:

$$
y_{t}=\mu_{s_{t}}+e_{t}, \quad e_{t} \sim N\left(0, \sigma_{s_{t}}^{2}\right)
$$

Where $y_{t}$ is observed datum and $s_{t}$ is condition or regime $s$ at time $t$, where $s_{t} \in\{1,2, \ldots, K\}, K$ are total of regimes. This research used JCI dan FTSE BM 100 index as variables. It is assumed that thee are two regimes, bullish and bearish. So the value of $K=2$.

If there are a number of different possible $K$ regimes, it is assumed that the changes between regimes controlled by Markov $K$-state chain are:

$$
p\left(s_{t}=j \mid s_{t-1}=i\right)=p_{i j}, \quad i, j=1, \ldots, \mathrm{K}
$$

with $p_{i j}$ is a chance of a transition or change from state $i$ to $j$. Then the transition opportunities are collected into the matrix as follows:

$$
P=\left[\begin{array}{ccc}
\mathrm{p}_{11} & \cdots & \mathrm{p}_{\mathrm{K} 1} \\
\vdots & \ddots & \vdots \\
\mathrm{p}_{1 \mathrm{~K}} & \cdots & \mathrm{p}_{\mathrm{KK}}
\end{array}\right]
$$

Markov Switching Autoregressive (MSAR) is the simplest combination of Markov Switching with time series models [16]. If it is assumed that $y_{t}$ the autoregressive whose mean and variance influenced by 2 regime changes, then the MS(2)-AR( $r)$ model can be written as follows [27]:

$$
\begin{gathered}
\Phi(\mathrm{L})\left(y_{t}-\mu_{s_{t}}\right)=e_{t} \\
\left(\mathrm{y}_{\mathrm{t}}-\mu_{\mathrm{s}_{\mathrm{t}}}\right)=\Phi_{1}\left(\mathrm{y}_{\mathrm{t}-1}-\mu_{\mathrm{s}_{\mathrm{t}-1}}\right)+\cdots+\Phi_{\mathrm{r}}\left(\mathrm{y}_{\mathrm{t}-\mathrm{r}}-\mu_{\mathrm{s}_{\mathrm{t}-\mathrm{r}}}\right)+\mathrm{e}_{\mathrm{t}}
\end{gathered}
$$

With $\mathrm{e}_{\mathrm{t}} \sim \operatorname{iidN}\left(0, \sigma_{\mathrm{s}_{\mathrm{t}}}^{2}\right)$, also $\mu_{\mathrm{s}_{\mathrm{t}}}$ and $\sigma_{\mathrm{s}_{\mathrm{t}}}^{2}$ are valued $\mu_{1}$ and $\sigma_{1}^{2}$ if the process are in regime 1 , and valued $\mu_{2}$ and $\sigma_{2}^{2}$ if the process are in regime 2 .

$\mathrm{y}_{\mathrm{t}}, \mathrm{y}_{\mathrm{t}-1}, \ldots, \mathrm{y}_{\mathrm{t}-\mathrm{r}}$ : observed data 
$\Phi_{1}, \Phi_{2}, \ldots, \Phi_{\mathrm{r}} \quad$ : autoregressive coefficient

$\mu_{\mathrm{s}_{\mathrm{t}}}, \mu_{\mathrm{s}_{\mathrm{t}-1}}, \ldots, \mu_{\mathrm{s}_{\mathrm{t}-\mathrm{r}}}$ : mean in time $t$ that influenced by regime changes

$\sigma_{\mathrm{s}_{\mathrm{t}}}^{2} \quad:$ variance in time $t$ that influenced by regime changes

$\mathrm{e}_{\mathrm{t}} \quad$ : residual in time $t$

The value of $\mu_{s_{t}}$ can determine whether a state / regime is bullish or bearish. With the provisions of $\mu_{2}<\mu_{1}$, then $s_{t}=1$ is the regime when the market is bullish and $\mathrm{s}_{\mathrm{t}}=2$ is the regime when the market is bearish.

\subsubsection{Beta and Portfolio formula}

Beta coefficients are defined by the covariance of stock returns with market returns, as part of a market portfolio variant. Beta values can be obtained through this following formula:

$$
\beta_{i}=\frac{\operatorname{Cov}\left(R_{i}, R_{M}\right)}{\sigma M^{2}}=\frac{\sum_{t-1}^{n}\left(R_{i t}-E\left(R_{i}\right)\right)\left(R_{M t}-E\left(R_{M}\right)\right)}{\sum_{t-1}^{n}\left(R_{M t}-E\left(R_{M}\right)\right)^{2}}
$$

Where $\beta_{i}$ is beta from stock $i$; $\operatorname{Cov}\left(R_{i}, R_{M}\right)$ is covariance between return from stock $i$ dan market return; $\sigma M^{2}$ is market return variance; $R_{i t}$ is return of stock $i$ in week $t ; E\left(R_{i}\right)$ is expected return from stock $i$; $\mathrm{R}_{\mathrm{Mt}}$ is market return in week $t$; and $\mathrm{E}\left(\mathrm{R}_{\mathrm{M}}\right)$ is market expected return.

Calculating expected portfolio returns can use this following formula:

$$
E\left(R_{p}\right)=\alpha_{p R}+\beta_{p} . E\left(R_{m}\right)
$$

Where $E\left(R_{p}\right)$ is portfolio expected return; $\alpha_{p R}$ is portofolio intercept; $\beta_{p}$ is portofolio beta; and $E\left(R_{m}\right)$ is market expected return.

If the expected portfolio return is known, then portfolio risk can be calculated from the value of the variance with this following formula:

$$
\sigma_{p}^{2}=\beta_{p}^{2} . \sigma_{M}^{2}+\left[\sum_{i=1}^{n} w_{i} \sigma_{e i}\right]^{2}
$$

Where $\sigma_{p}^{2}$ is portofolio total risk; $\beta_{p}^{2}$ is portofolio beta; $\sigma_{M}^{2}$ is market return variance; $w_{i}$ is stock $i$ proportion; and $\sigma_{e i}^{2}$ is error.

If the prevailing assumption is that the contribution of the proportion of funds from $\mathrm{n}$ share assets in the portfolio composition is the same, the nonsystematic risk in the portfolio will decrease to near zero if the investor adds nshare assets to the portfolio. Based on the assumption that the funds shared is in the same proportion, portfolio risk is only influenced by the market, or bounded by beta and market return variance. Portfolio risk can be calculated using the following formula:

$$
\sigma_{p}^{2}=\beta_{p}^{2} \cdot \sigma_{M}^{2}
$$

Portfolio performance evaluation should be done after selecting a portfolio. In this study, Sharpe ratio is used due to its suitability because the measurement 
represents a large portion of the overall portfolio [28]. Portfolio performance evaluation in this study uses the Sharpe Ratio, with the following formula:

$$
\text { Sharpe Ratio }=\frac{R_{p}-R_{f}}{\sigma_{T R}}
$$

Where $R_{p}$ is portfolio returns over the observed time period; $R_{f}$ is risk free asset returns over the observed time period; and $\sigma_{T R}$ is portofolio standard deviation over the observed time period. The higher the Sharpe ratio value, the better the portfolio performance.

\section{Empirical Results}

\subsection{Bullish and Bearish Analysis in Indonesian and Malaysian Stock Market}

The first objective is to identify the bullish and bearish periods in the Indonesian and Malaysian capital markets. Jakarta Composite Index (JCI) and Financial Times Stock Exchange Bursa Malaysia 100 Index (FTSE BM 100) weekly price data from 2014 to 2019 are used to represent both market.

Table 1. Augmented Dickey-Fuller test statistic for JCI and FTSE BM 100 return data

\begin{tabular}{ccc}
\hline Market & T-statistic & Probability \\
\hline Indonesia & -18.94585 & 0.3717 \\
Malaysia & -17.36725 & 0.2049 \\
\hline $1 \%$ critical value: -3.451214 & & \\
\hline
\end{tabular}

The data to be used in this study must follow the assumptions of stationarity. Table 1 shows the results of Augmented Dickey Fuller (ADF) test from the JCI and FTSE BM 100 weekly return. From table it can be seen that the t-statistic value on both indexes is smaller than the critical value of the test. Thus, the weekly return data of both index is stationary and can be used for next step.

Regime changes analysis using Markov Switching Autoregressive (MSAR) is conducted to determine the bullish and bearish period in the stock market. Table 2 shows the results of the MSAR test on both index. In Indonesia, variable $\mathrm{C}$ in regime 1 shows a negative value (-0.005). Meanwhile, variable $\mathrm{C}$ in regime 2 gives positive value (0.003). Because regime 1 has negative value, thus is classified as a bearish condition $\left(\mathrm{P}\left(\mathrm{S}_{(\mathrm{t})}=1\right)\right.$, and regime 2 is classified as a bullish condition $\left(P\left(S_{(t)}=2\right)\right.$. In Malaysia, variable $C$ in regime 1 gives a positive value which equal to 0.001 , while the regime 2 gives a negative value which 
equal to -0.001 . Thus, regime 1 is classified as a bullish condition $\left(\mathrm{P}\left(\mathrm{S}_{(\mathrm{t})}=1\right)\right.$, while regime 2 is classified as a bearish condition $\left(\mathrm{P}\left(\mathrm{S}_{(\mathrm{t})}=2\right)\right.$.

Table 2. Markov-switching score on JCI and FTSE BM 100 return data

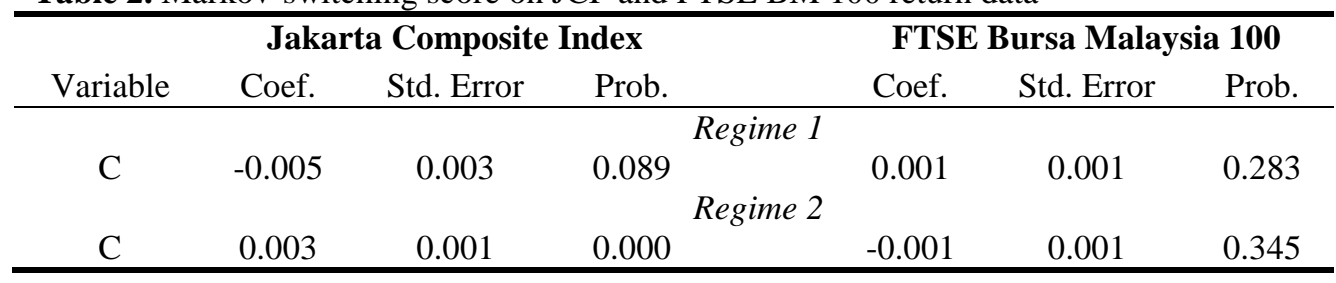

Probabilities for regime changes between one regime and another and expected duration for each regime can be seen in Table 3. In Indonesia, the probabilities that the market state change from bullish into bearish is $3.53 \%$. While the probability from bearish into bullish is $11.76 \%$. The probabilities that the bullish condition keep stays in bullish and the bearish keep stays in bearish condition are respectively $96.46 \%$ and $88.23 \%$. The average time the JCI is in a bullish condition is 28.3 weeks, while in a bearish condition for 8.5 weeks. In Malaysia, the probability that the regime change from bullish into bearish condition in the following week is $1.73 \%$. While the chance of changing from bearish into bullish in the following week is $1.47 \%$. Chance of the market stays in its condition are $98.27 \%$ for bullish and $98.52 \%$ for bearish. The average bullish time in FTSE BM 100 is 57.8 weeks, and 67.6 weeks in bearish.

Table 3. Constant transition probabilities and expected duration on JCI and FTSE BM 100

\begin{tabular}{cccccc}
\hline \multicolumn{5}{c}{ Jakarta Composite Index } & Constant transition probabilities \\
\hline \multirow{5}{*}{ Regime } & Bullish & Bearish & Regime & Bullish & Bearish \\
\hline Bullish & 0.964669 & 0.035331 & Bullish & 0.982697 & 0.017303 \\
Bearish & 0.117655 & 0.882345 & Bearish & 0.014791 & 0.985209 \\
\hline \multicolumn{5}{c}{ Constant expected durations (weeks) } \\
& Bullish & Bearish & Bullish & Bearish \\
\hline & 28.3 & 8.5 & 57.8 & 67.6 \\
\hline
\end{tabular}

Table 4 shows the duration of each market state. During 2014 until 2019, there were 5 bullish periods and 4 bearish periods identified on the JCI. The longest duration occurs on 15 January 2014 - 1 April 2015 or 64 weeks for bullish conditions, and on 8 April 2015 - 28 October 2015 or 30 weeks for bearish conditions. The shortest duration occurs from 22 May 2019 to 18 December 2019 or for 31 weeks for bullish conditions and on 24 April 2019 15 May 2019 or for 4 weeks for bearish conditions. Meanwhile, the FTSE BM 100 had 3 bullish and 3 bearish periods. The longest bullish period occurred on 
4 May 2016 - 15 November 2017 or for 81 weeks. The longest bearish period occurred on 22 November 2017 - 21 August 2019 or for 92 weeks. The shortest bullish period occurred on 28 August 2019 - 23 October 2019 or for 9 weeks. The shortest bearish period occurred on 30 October 2019 - 18 December 2019 or for 8 weeks. JCI and FTSE BM 100's bullish bearish price mapping can be seen in Figure 2.

Table 4. Time and duration of bullish and bearish conditions in JCI and FTSE BM 100 index

\begin{tabular}{ccccc}
\hline & \multicolumn{2}{c}{ Jakarta Composite Index } & \multicolumn{2}{c}{ FTSE Bursa Malaysia 100 } \\
\hline Cond. & Period & $\begin{array}{c}\text { Length } \\
\text { (weeks) }\end{array}$ & Period & $\begin{array}{c}\text { Length } \\
\text { (weeks) }\end{array}$ \\
\hline Bull 1 & 15 Jan 2014 - 1 Apr 2015 & 64 & 15 Jan 2014 - 10 Sep 2014 & 35 \\
Bear 1 & 8 Apr 2015 - 28 Oct 2015 & 30 & 17 Sep 2014 - 27 Apr 2016 & 85 \\
Bull 2 & 4 Nov 2015 - 26 Oct 2016 & 52 & 4 May 2016 - 15 Nov 2017 & 81 \\
Bear 2 & 2 Nov 2016 - 7 Dec 2016 & 6 & 22 Nov 2017 - 21 Aug 2019 & 92 \\
Bull 3 & 14 Dec 2016 - 21 Feb 2018 & 63 & 28 Aug 2019 - 23 Oct 2019 & 9 \\
Bear 3 & 28 Feb 2018 - 22 Aug 2018 & 26 & 30 Oct 2019 - 18 Dec 2019 & 8 \\
Bull 4 & 29 Aug 2018 - 17 Apr 2019 & 34 & - & - \\
Bear 4 & 24 Apr 2019 - 15 May 2019 & 4 & - & - \\
Bull 5 & 22 May 2019 - 18 Dec 2019 & 31 & - & - \\
\hline
\end{tabular}

\subsection{Contrarian Stock Identification}

The next objective is to identify contrarian stock in each bullish and bearish period for both Indonesian and Malaysian stock market. But before that, it must be ensured that the stock to be selected in the portfolio have met the assumption of normality. After that, calculate the return and beta value from every stock that pass the normality test in each period. Stock that has positive return and negative beta value categorized as contrarian stocks. Regime duration, total shares that pass normality test, and number of contrarian stock in every period shown in Table 5.

In Indonesia, contrarian stocks can be found in every period. Contrarian stocks are easier to found in bearish conditions than in bullish conditions. The $2^{\text {nd }}$ bearish period is the period where there are the most contrarian stocks, where $10 \%$ from the sample, or as many as 33 stocks, were contrarian stocks. Meanwhile, in Malaysia, contrarian stocks are only found in bullish periods. There is no contrarian stock in the bearish period. This is quite interesting, considering theoretically when the market is in a bullish condition, stocks with negative beta tend to bearish. However, despite being in a bearish condition (as opposed to a bullish market condition), these stocks were able to record positive returns. 
The existence of contrarian stocks only in bullish period is expected to occur due to several factors. First, when the market is bearish, other stocks move pessimistic about market conditions. So that no stock move against market movements and produce a positive beta value. Second, if there is a stock moves against the market, those stock is not having positive return during that period.
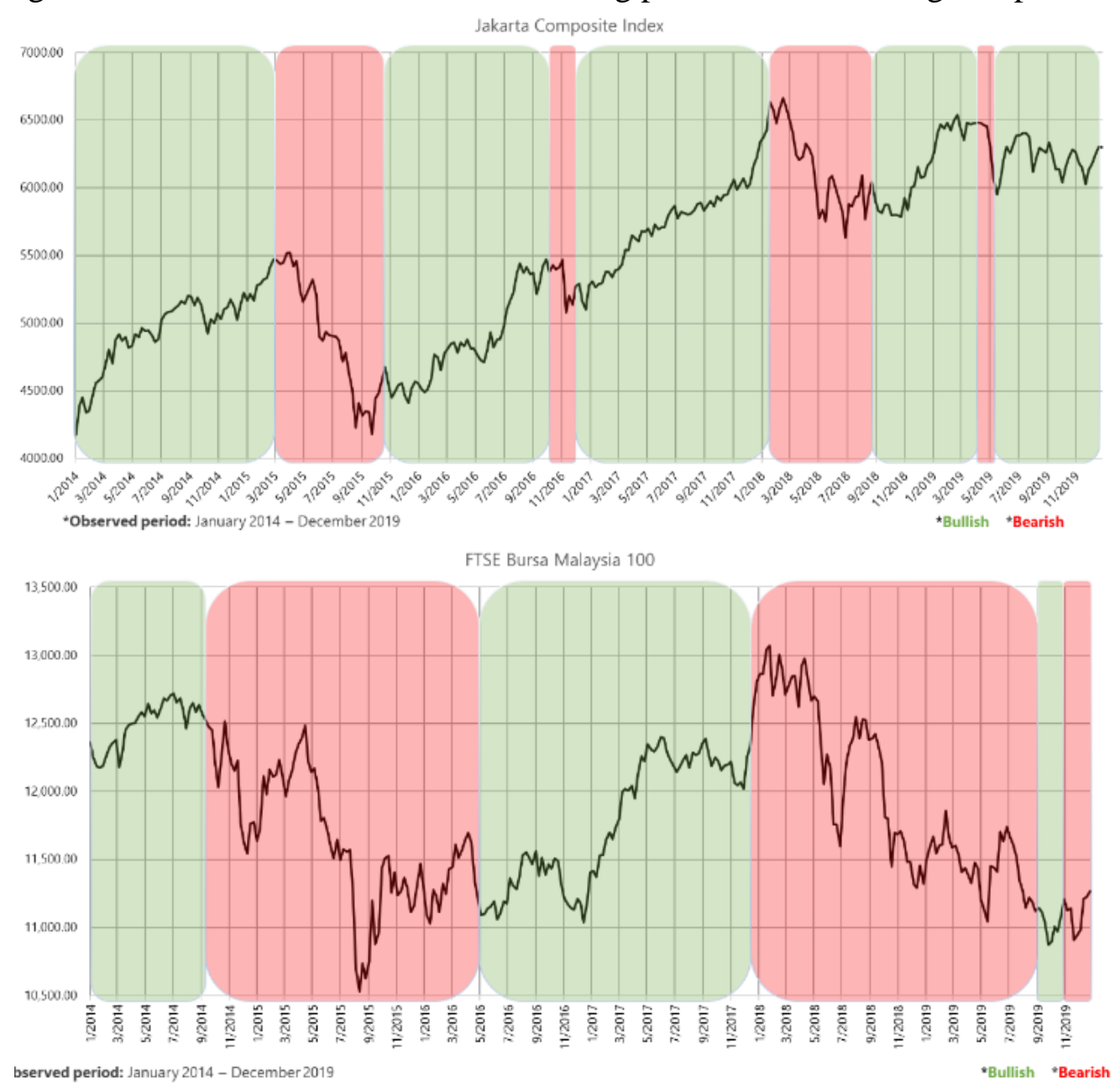

Fig. 2. Market state mapping on JCI and FTSE BM 100 index from $2014-2019$. 
Table 5. Total of contrarian stock identified

\begin{tabular}{cccccccc}
\hline Cond. & $\begin{array}{c}\text { Length } \\
\text { (weeks) }\end{array}$ & $\begin{array}{c}\text { Total } \\
\text { stock* }\end{array}$ & $\begin{array}{c}\text { Contrarian } \\
\text { Stock }\end{array}$ & Cond. & $\begin{array}{c}\text { Length } \\
\text { (weeks) }\end{array}$ & $\begin{array}{c}\text { Total } \\
\text { stock* }\end{array}$ & $\begin{array}{c}\text { Contrarian } \\
\text { Stock }\end{array}$ \\
\hline \multicolumn{7}{c}{ Indonesia } \\
\hline Bull 1 & 64 & 84 & 3 & Bear 1 & 30 & 179 & 1 \\
Bull 2 & 52 & 102 & 7 & Bear 2 & 6 & 331 & 33 \\
Bull 3 & 63 & 71 & 3 & Bear 3 & 26 & 110 & 5 \\
Bull 4 & 34 & 150 & 14 & Bear 4 & 4 & 213 & 20 \\
Bull 5 & 31 & 99 & 5 & & & & \\
\hline \multicolumn{7}{c}{} & \multicolumn{7}{c}{ Malaysia } \\
\hline Bull 1 & 35 & 51 & 5 & Bear 1** & 85 & 29 & 0 \\
Bull 2 & 81 & 30 & 2 & Bear 2** & 92 & 20 & 0 \\
Bull 3 & 9 & 78 & 20 & Bear 3** & 8 & 8 & 0 \\
\hline
\end{tabular}

* Number of stocks that have passed the normality assumption, from population 433 stock in JCI and 100 stock in FTSE BM 100 index

** There is no contrarian stock in this period.

\subsection{Portfolio Performance Comparison}

After we identified the contrarian stock in each period, the next step is selecting an optimum portfolio. Optimum portfolio selection is done using the Markowitz's mean-variance method. Portfolio selection, both in Indonesia and in Malaysia, are divided into two parts: a portfolio with contrarian stocks and a portfolio without contrarian stocks.

Table 6. Sharpe ratio, risk, and return score of the efficient portfolio on every period

\begin{tabular}{|c|c|c|c|c|c|c|}
\hline \multirow{2}{*}{ Cond. } & \multicolumn{3}{|c|}{ Portfolio with contrarian stock } & \multicolumn{3}{|c|}{ Portfolio without contrarian stock } \\
\hline & Sharpe ratio & Risk & Return & Sharpe ratio & Risk & Return \\
\hline \multicolumn{7}{|c|}{ Indonesia } \\
\hline Bull 1 & 0.7541 & 0.0094 & 0.0073 & 0.6519 & 0.0117 & 0.0079 \\
\hline Bear 1 & 0.3552 & 0.0144 & 0.0054 & 0.3525 & 0.0140 & 0.0052 \\
\hline Bull 2 & 0.8135 & 0.0096 & 0.0086 & 0.7375 & 0.0126 & 0.0101 \\
\hline Bear 2 & $1.1262 \mathrm{e}+07$ & $3.349 \mathrm{e}-10$ & 0.0047 & $5.5269 e+06$ & $6.1021 \mathrm{e}-10$ & 0.0043 \\
\hline Bull 3 & 0.6754 & 0.0143 & 0.0102 & 0.6057 & 0.0160 & 0.0103 \\
\hline Bear 3 & 0.8040 & 0.0057 & 0.0053 & 0.4955 & 0.0109 & 0.0062 \\
\hline Bull 4 & 1.8768 & 0.0026 & 0.0059 & 1.0128 & 0.0088 & 0.0099 \\
\hline Bear 4 & $9.4750 \mathrm{e}+07$ & $7.0229 \mathrm{e}-11$ & 0.0076 & $3.9247 \mathrm{e}+07$ & $1.7345 \mathrm{e}-10$ & 0.0077 \\
\hline Bull 5 & 1.3829 & 0.0017 & 0.0032 & 0.6242 & 0.0193 & 0.0128 \\
\hline \multicolumn{7}{|c|}{ Malaysia } \\
\hline Bull 1 & 1.0915 & 0.0055 & 0.0061 & 0.8949 & 0.0083 & 0.0076 \\
\hline Bear $1 *$ & & --- & & 0.2335 & 0.0246 & 0.0061 \\
\hline Bull 2 & 0.6076 & 0.0146 & 0.0090 & 0.5599 & 0.0178 & 0.0101 \\
\hline Bear $2 *$ & & --- & & 0.2362 & 0.0339 & 0.0085 \\
\hline Bull 3 & $6.1632 \mathrm{e}+07$ & $5.9672 \mathrm{e}-11$ & 0.0044 & $3.5624 \mathrm{e}+07$ & $5.4335 \mathrm{e}-11$ & 0.0027 \\
\hline Bear $3 *$ & & --- & & 0.3012 & 0.0153 & 0.0051 \\
\hline
\end{tabular}

* In this period, no contrarian stock identified. 
The optimum portfolio selection is done in all market states that have been analyzed in the first sub-chapter. But since there is no contrarian stock in the bearish period in Malaysia, the portfolio selection with contrarian stocks is only done in bullish periods. The results of the Sharpe ratio, risk, and return values of the two sets of optimal portfolios analyzed can be seen in Table 6 .

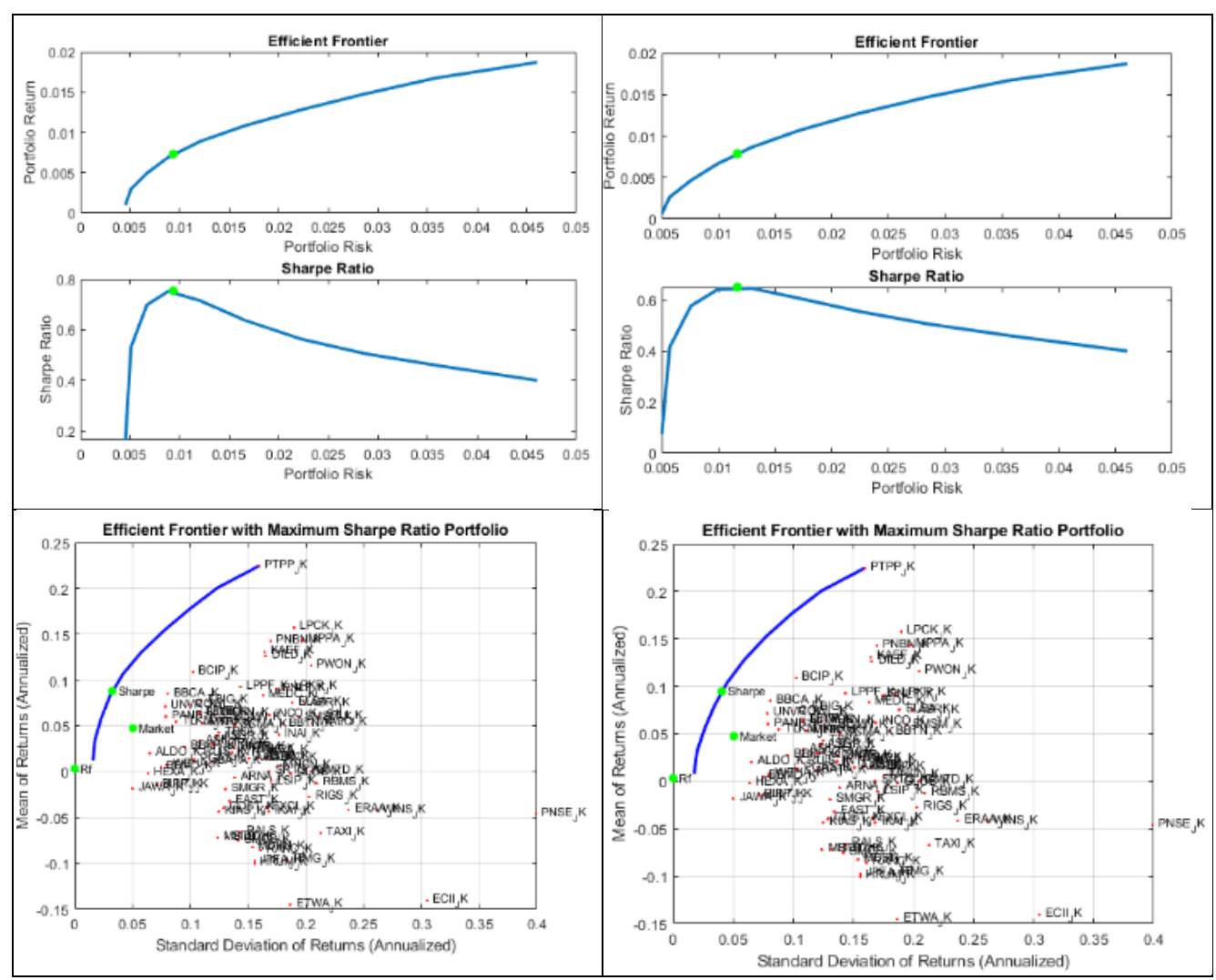

Fig. 4. Sharpe ratio and efficient frontier curve between portfolio with contrarian stock (left) and without contrarian stock (right) in Indonesia's $1^{\text {st }}$ bullish period.

Portfolios with contrarian stock have a bigger Sharpe ratio than portfolios without contrarian stocks in all periods, both in Indonesia and Malaysia. The bigger the Sharpe ratio means that the better the portfolio's performance. In Indonesia, contrarian stocks were able to contribute to increasing the Sharpe ratio by an average of $61.4 \%$. The $141 \%$ increase in Bearish 4 was the Sharpe ratio's biggest improvement. Meanwhile, in Malaysia, contrarian stocks were able to increase the Sharpe ratio by an average of $34.5 \%$. The biggest increase occurred in the Bullish 3 period, which was 73\%. Figure 4 shows the Sharpe ratio comparison between the two portfolios in the Bullish 1 period in Indonesia 
and Figure 5 shows the Sharpe ratio comparison between the two portfolios in the Bullish 1 period in Malaysia. The green dot shows the optimal portfolio combination point. At the same optimal point, it can be seen that portfolios with contrarian stocks have a higher Sharpe ratio compared to portfolios without contrarian stocks.

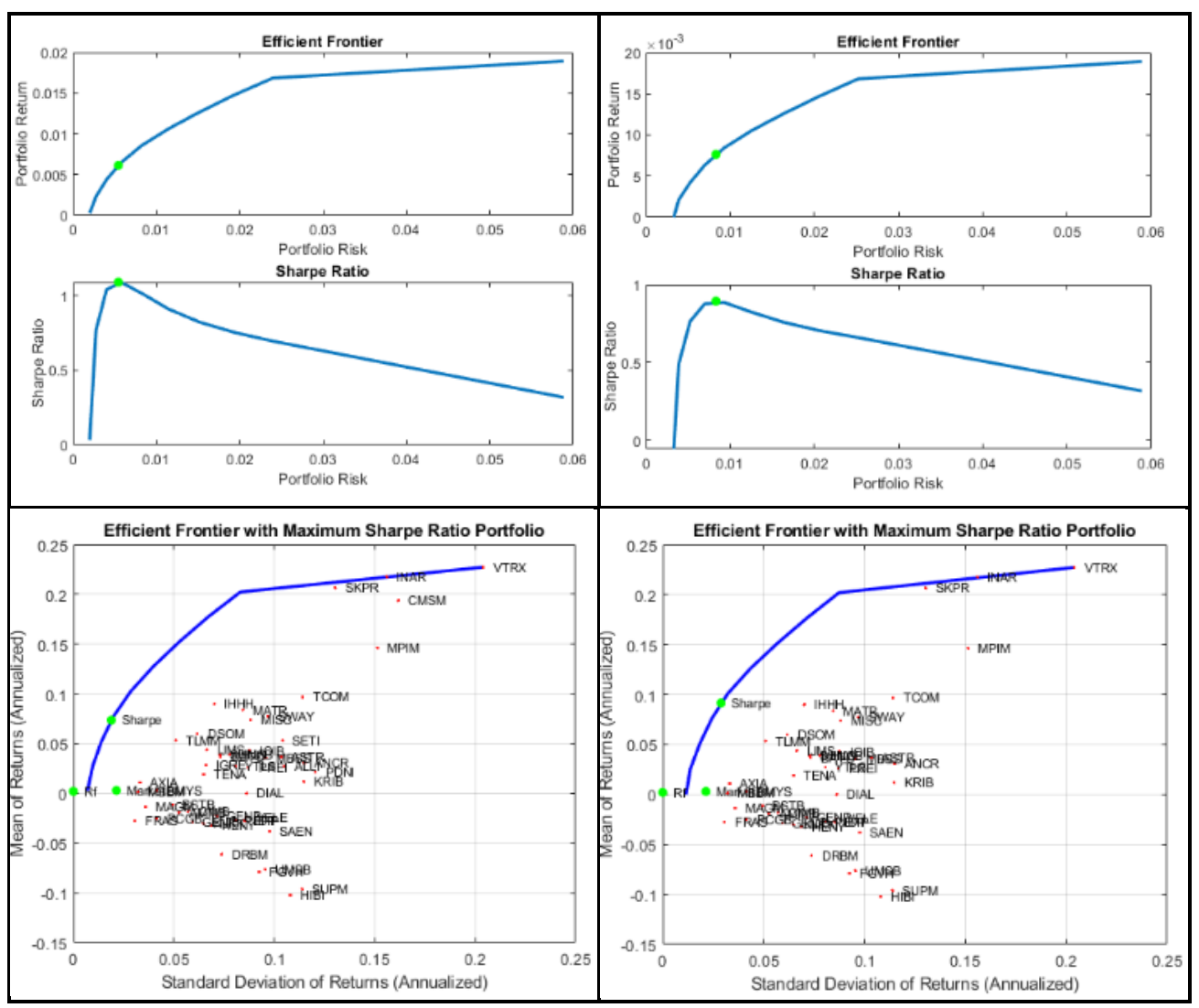

Fig. 5. Sharpe ratio and efficient frontier curve between portfolio with contrarian stock (left) and without contrarian stock (right) in Malaysia's bullish 1 period.

Portfolios that including contrarian stocks tend to have lower levels of risk. In both countries, the average risk reduction is $33.9 \%$. The greatest risk reduction occurred in Indonesia in bullish 5, where the level of portfolio risk with contrarian shares decreased by $91.19 \%$. In Malaysia, the greatest risk reduction occurred in bullish 1 , which was $33.7 \%$. However, not all portfolio's risk has been reduced. In the Bearish 1 period in Indonesia, the addition of contrarian stocks in the portfolio caused an increase in the portfolio's risk by $2.9 \%$. However, the increase in risk is still smaller than the increase in return. In the same period, the increase in return was 3.8\%. In Malaysia, there was also 
a $9.8 \%$ increase in portfolio risk in the Bullish 3 period. What is even more surprising, is that the increase in risk was compensated by the very large increase in portfolio return, which was $63 \%$.

Overall, the addition of contrarian stocks to the portfolio makes the portfolio's return decreased. This is consistent with the axiom of "high risk, high return". However, the decline in portfolio return was still smaller than the reduction in risk. Or in other words, with the same level of risk, a portfolio with contrarian stocks is able to provide a higher rate of return than a portfolio without contrarian stocks.

The paired difference test is used to prove whether there is a significant difference in the value of the Sharpe ratio, risk, and return on the portfolio. From the test results described in Table 7, the Sharpe ratio value did not have a significant difference. Insignificant differences were also found in the return value obtained. The only significant difference is the risk value. Portfolios with contrarian stocks are proven to reduce the risk of these portfolios and are significantly different from portfolios without including contrarian stocks. The results of this study support research conducted by Respati [5], where the value of portfolio risk by including negative beta stocks and positive returns is significantly different from portfolios without negative beta stocks and positive returns.

Table 7. Paired different test between Portfolio with and without contrarian stocks

\begin{tabular}{cccccc}
\hline & Mean & Std. Dev & $\begin{array}{c}\text { Std. Error } \\
\text { Mean }\end{array}$ & t & $\begin{array}{c}\text { Sig. } \\
\text { (2-tailed) }\end{array}$ \\
\hline Sharpe Pre-Post & $-7.27 \mathrm{E}+06$ & $1.69 \mathrm{E}+07$ & $4.89 \mathrm{E}+06$ & -1.487 & 0.165 \\
Risk Pre-Post & 0.0038 & 0.0054 & 0.0016 & 2.443 & $0.033^{*}$ \\
Ret Pre-Post & 0.0014 & 0.0029 & 0.0008 & 1.636 & 0.130 \\
\hline
\end{tabular}

Pre $=$ Portfolio without contrarian stock. Post $=$ Portfolio with contrarian stock.

*Differ significatnly between portfolio without contrarian stock and with contrarian stock at $95 \%$ confidence level

\section{Conclusions}

This research provides new insights of how useful the contrarian strategy is. The results show that in the period of 2014 to 2019 , there are 5 bullish periods and 4 bearish periods identified in Indonesia, and 3 bullish periods and 3 periods identified in Malaysia. the value of constant expected duration in Malaysia is greater than in Indonesia for both the bullish and bearish periods, indicating that the bullish and bearish conditions will last longer, and the opportunity to change conditions from bullish to bearish or vice versa, is not as big as in Indonesia. 
Contrarian stocks were identified on both bullish and bearish in Indonesia, but only on bullish condition in Malaysia. This implies that we can't find stocks that go upward and have positive return when the market in Malaysia is in bearish condition. However, the contrarian stocks in Indonesia are easier to find in bearish condition. This implies that when the market in Indonesia go down, there are some stocks that going up with positive return. And when these contrarian stocks included in portfolio selection, the contrarian stocks successfully contributed to minimize the portfolio risk and give greater portfolio performance. Level of risk from portfolio with contrarian stock also differ significantly with portfolio without contrarian stock.

This study also provides some implications for investors. First, risk-averse and risk-neutral investors should include contrarian stock to their portfolio. The portfolio with contrarian stock shows a lower risk, so it will be suitable for those two kinds of investors. The lower the risk, the safer the investment would be. So, all the stakeholders, especially the investors, could conduct the investment more sustainably. Secondly, the investor needs to rebalance their portfolio periodically. In this research, portfolio combination in each period is a different one to another. It means that each period has its difference in optimum combination and the optimum portfolio in this period may differ to the previous and next period. And lastly, the portfolio selection method is important if the investor wants to include contrarian stock in their portfolio. The investor should use the Markowitz mean-variance model because the contrarian stock will not have excluded due to ERB calculation, not like the single index model method.

\section{Acknowledgments}

Our thanks to the International Collaboration Office (ICO) IPB University, School of Business and Economics, UPM Malaysia, and Department of Management, IPB University for the support and collaboration in the Research Attachment Program.

\section{References}

[1] De Bondt WFM, Thaler R. Does the Stock Market Overreact? J Finance. 1985;40(3):793-805.

[2] De Bondt WFM, Thaler R. Further Evidence On Investor Overreaction and Stock Market Seasonality. J Finance. 1987;42(3):557-81.

[3] Azis M, Mintarti S, Nadir M. Manajemen Investasi Fundamental, Teknikal, Perilaku Investor dan Return Saham. Yogyakarta (ID): Deepublish; 2015.

[4] Respati P, Purwanto B, Irwanto AK. Estimasi Bullish dan Bearish dengan Model Perpindahan Markov dan Risiko Sistematis (beta) dengan Model Penilaian Modal Sharpe dalam Investasi Saham di Bursa Efek Indonesia, Tahun 2011 - 2016. J Manaj dan Organ. 2017;8(3):221-35. 
[5] Respati P. Anomali "Beta Negatif" dan Kontribusinya terhadap Pembentukan Portfolio Optimal dalam Kondisi Pasar Bullish dan Bearish. Institut Pertanian Bogor; 2018.

[6] Chen P, Yang H. Markowitz's Mean-Variance Asset - Liability Management with Regime Switching : A Multi-Period Model. Appl Math Financ. 2011;18(1):29-50.

[7] Samuelson PA. Lifetime Portfolio Selection By Dynamic Stochastic Programming. Rev Econ Stat. 1969;51(3):239-46.

[8] Merton RC. Optimum Consumption and Portfolio Rules in a Continuous-Time Model. J Econ Theory. 1971;3:373-413.

[9] Merton RC. Lifetime Portfolio Selection under Uncertainty: The Continuous-Time Case. Rev Econ Stat. 1969;51(3):247-57.

[10] Neftci SN. Are Economic Time Series Asymmetric over the Business Cycle? J Polit Econ. 1984;92(2):307-28.

[11] Zhou XY, Yin G. Markowitz's Mean-Variance Portfolio Selection with Regime Switching: A Continuous-time Model. Soc Ind Appl Math. 2003;42(4):1466-82.

[12] Elliott RJ, Siu TK. Robust Optimal Portfolio Choice Under Markovian Regimeswitching Model. Methodol Comput Appl Probab. 2009;11:145-57.

[13] Guidolin M, Timmermann A. Asset Allocation Under Multivariate Regime Switching. J Econ Dyn Control. 2007;31:3503-44.

[14] Tandelilin E. Beta pada Pasar Bullish dan Bearish: Studi Empiris di Bursa Efek Jakarta. J Ekon dan Bisnis Indones. 2001;16(3):261-72.

[15] Fabozzi FJ, Francis JC. Stability Tests for Alphas and Betas Over Bull and Bear Market Conditions. J Finance. 1977;32(4):1093-9.

[16] Ariyani FD, Warsito B, Yasin H. Pemodelan Markov Switching Autoregressive. J Gaussian. 2014;3(3):381-90.

[17] Hamilton JD. A New Approach to The Economic Analysis of Nonstationary Time Series and The Business Cycle. Econometrica. 1989;57(2):357-84.

[18] Chu C-SJ, Santoni GJ, Liu T. Stock Market Volatility and Regime Shifts in Returns. Inf Sci (Ny). 1996;94:179-90.

[19] Huang Y-F, Startz R. Improved Recession Dating Using Stock Market Volatility. In 2019.

[20] Wasim A, Bandi K. Identifying Regime Shifts in Indian Stock Market: A Markov Switching Approach. Munich Pers RePEc Arch. 2011;1-22.

[21] Markowitz HM. The Early History of Portfolio Theory: 1600-1960. Financ Anal J. 1999;55(4):5-16.

[22] Markowitz H. Portfolio Selection. J Finance. 1952;7(1):77-91.

[23] Sharpe WF. A Simplified Model for Portfolio Analysis. Manage Sci. 1963;9(2):27793.

[24] Amanah NK. Index of Moral Bounded: Manajemen Portofolio dengan Paradigma Kepatuhan Syariah (Study of Indonesia Market). Institut Pertanian Bogor; 2019.

[25] Brockwell PJ, Davis RA. Introduction to Time Series and Forecasting. New York: Springer; 2002.

[26] Hamilton JD. Specification Testing in Markov-switching Time-series Models James. J Econom. 1996;70:127-57.

[27] Kim C, Nelson CR. State-Space Models with Regime Switching. Classical and GibbsSampling Approaches with Applications. London: The MIT Press; 1999. 297 p.

[28] Scholz H, Wilkens M. Investor Specific Performance Measurement: A Justification of Sharpe Ratio and Treynor Ratio. Int J Financ. 2005;17(4):1-21. 